\title{
Neural Plasticity After Spinal Cord Injury
}

\author{
Yuemin Ding, Abba J. Kastin, and Weihong Pan * \\ Pennington Biomedical Research Center, Baton Rouge, LA 70808, USA
}

\begin{abstract}
Spinal cord injury (SCI) has devastating physical and socioeconomical impact. However, some degree of functional recovery is frequently observed in patients after SCI. There is considerable evidence that functional plasticity occurs in cerebral cortical maps of the body, which may account for functional recovery after injury. Additionally, these plasticity changes also occur at multiple levels including the brainstem, spinal cord, and peripheral nervous system. Although the interaction of plasticity changes at each level has been less well studied, it is likely that changes in subcortical levels contribute to cortical reorganization. Since the permeability of the blood-brain barrier (BBB) is changed, SCI-induced factors, such as cytokines and growth factors, can be involved in the plasticity events, thus affecting the final functional recovery after SCI. The mechanism of plasticity probably differs depending on the time frame. The reorganization that is rapidly induced by acute injury is likely based on unmasking of latent synapses resulting from modulation of neurotransmitters, while the long-term changes after chronic injury involve changes of synaptic efficacy modulated by long-term potentiation and axonal regeneration and sprouting. The functional significance of neural plasticity after SCI remains unclear. It indicates that in some situations plasticity changes can result in functional improvement, while in other situations they may have harmful consequences. Thus, further understanding of the mechanisms of plasticity could lead to better ways of promoting useful reorganization and preventing undesirable consequences.
\end{abstract}

\section{Keywords}

Spinal Cord Injury; Plasticity; Reorganization; Cortex; Blood-Brain Barrier

\section{INTRODUCTION}

Spinal cord injury (SCI) results in transient or permanent interruption of motor, sensory, or autonomic function. The outcome after injury is largely determined by the topographical organization of the spinal cord and the site of the insult. For instance, disruption of nerve fiber bundles that convey ascending sensory and descending motor information is especially devastating, since it leads to pronounced sensorimotor dysfunction of all body parts below the lesion site.

SCI primarily affects young adults. Fifty-three percent of SCI occurs among individuals between 16 and 30 years of age, and the mean age at injury is 32.6. In the United States, the causes of traumatic SCI are multiple (Fig. 1): motor vehicle crashes account for $40.9 \%$ of the SCI cases reported. The next largest contributor is falls (22.4\%) followed by acts of violence (21.6\%) and recreational sporting activities (7.5\%). It has been estimated that the

(C) 2005 Bentham Science Publishers Ltd.

*Address correspondence to this author at the Pennington Biomedical Research Center, 6400 Perkins Road, Baton Rouge, LA 70808, USA; Tel: (225) 763-2707; Fax: (225) 763-0261; weihong.pan@pbrc.edu. 
annual incidence of SCI is about 40 cases per million population in the United States or about 11,000 new cases each year. The number of people in the United States who have SCI reached about 243,000 persons as of December 2003.

Patients with severe SCI can be quadraplegic (paralysis of the four limbs) or paraplegic (paralysis of the lower part of the body). Quadraplegia results from high cervical lesions while paraplegia results from lesions below the cervical level. SCI can also be classified as complete or incomplete. Both classes of injury represent different challenges for clinical treatment and for research. In cases of complete spinal cord lesion, the main challenge is regeneration of fibers across the lesion site. However, lack of adequate regeneration in the adult central nervous system (CNS) often leads to permanent functional deficits. Essentially, there are two main explanations for this: the CNS neurons themselves lack the capacity to undergo axonal regeneration and they are repressed by an inhibitory CNS microenvironment [1]. Both of these may contribute to the failure of regeneration.

Fortunately, there has been a growing awareness that the capacity of neurons and their axons to regenerate is extensively preserved throughout adulthood. Supporting this issue is the observation that manipulations of the environment of an injured neuron or its lesioned axon prevent cell death and induce axonal growth to a certain extent. Actually, even without treatment and despite the presence of axonal growth-inhibitory molecules at the lesion site, functional recovery can be seen in about $40 \%$ of SCI patients [2,3], as well as in SCI animal models $[4,5]$. It is now clear that in addition to compensatory behavioral strategies, spontaneous injury-induced structural reorganization (plasticity) in the adult CNS can occur over a protracted time course, which at least partially contributes to functional recovery.

The process of plasticity consists of changes in the activation pattern either of structure or function that involves alteration of the strength of existing connections and sprouting of new neural connections. There is now considerable evidence that cortical representation of body parts is continuously modulated in response to activity, behavior, and skill acquisition [6,7]. Reorganization of cortical representation occurs after CNS injuries such as stroke [8] or SCI [9], which may account for recovery of function after injury. Although it is likely that some of the reorganization after injury takes place in the cortex, plasticity changes may also occur in subcortical structures such as the thalamus, brainstem, and spinal cord.

This review concentrates on neural plasticity after SCI. We will first describe changes after chronic injury since most studies in experimental animals and human beings have focused on these changes; this is followed by a review of acute changes occurring immediately after injury, which have received less attention. Findings from experimental animals and human beings are presented in sequence. We will then discuss the possible mechanisms involved. Finally, we will examine the functional significance of these changes.

\section{NEURAL PLASTICITY AFTER CHRONIC INJURY}

Because longstanding injuries tend to cause extensive cortical map changes, most work has focused on the changes observed weeks, months, or years after injury. In addition to the causes leading to traumatic SCI described above, chronic injuries may be caused by many pathological conditions, such as spinal cord degeneration, mechanical compression by tumor or severe spondylosis, and vascular insufficiency caused by hypoxia, ischemia, or hemorrhage. The pathophysiology generally involves edema, inflammation, and cell death. The injuries can affect an individual in many ways. Symptoms are related to the level of cord injury and damage to specific neuronal tracts within the cord. Damage to sensory afferents cause a lack or altered response to pain and temperature stimuli, two-point discrimination, vibration, and proprioception, whereas those to motor efferents result in 
weakness or immobility. However, cortical reorganization and functional recovery after SCI have been observed both in animals and human studies.

\section{Experimental Animal Studies after Chronic SCI}

Most studies on cortical plasticity after SCI have focused on the somatosensory cortex $[10,11]$. Each subdivision of this cortical area, such as the anterior parietal cortex and cytoarchitectonic areas 3a, 3b, 1 and 2, contains a systematic map of body parts. Since the representations of sensory inputs in the somatosensory cortex are topographic, the loss of input from any given body part deactivates a portion of each representation, the size of which reflects the number of afferents that have been injured. This specific property makes it possible to assess somatosensory cortical reorganization after injury.

The most detailed analyses of somatosensory cortical plasticity after SCI in monkeys focus on changes after dorsal column sections at cervical levels C3-5 [12,13]. Six to eight months after a complete unilateral section, the hand map in cortical areas $3 \mathrm{a}, 3 \mathrm{~b}$, and 1 is largely reactivated by uninjured input from the lower face and other parts that typically enter above the section. This also has been observed in monkeys with incomplete sections, in which neurons responding to the few spared areas of input from the hand also become responsive to the face [13]. Thus, responsiveness to hand afferents do not prevent these neurons from subsequent plasticity. In less extensive injuries, more rapid reactivation of the area $3 \mathrm{~b}$ hand map by spared hand input has been seen within weeks. These findings suggest that changes in the cortical map depend on the availability of spared connections and postinjury survival time. Therefore, more confined injuries with greater sparing of input from the hand tend to earlier expansion of these hand maps, whereas larger injuries tend to greater expansion of the face maps after prolonged recovery periods.

The topographical organization of the primary motor cortex (M1) is not static, but undergoes considerable reorganization after SCI as well as other types of central and peripheral lesions. For instance, several studies have reported a reorganization of M1 after peripheral nerve lesions or limb amputation in rats and monkeys [14-17]. These plasticity changes also have been seen after focal ischemic infarcts in adult monkeys [18] and SCI in rats [18,19]. Regardless of the species used, the results show that motor cortical territories controlling intact body parts tend to enlarge and invade those that have lost their peripheral targets (Fig. 2) [19].

Spinal cord injuries cause structural changes in subcortical substrates. Thalamic changes generally resemble the cortical changes mentioned above. For instance, 20 months after cervical sections, the facial representative area has expanded into a region that would normally represent the hand in the ventroposterior lateral (VPL) nucleus [18]. Brainstem sprouting of new peripheral input also has been seen in monkeys after chronic cervical section [12].

At the cellular level, while the primary injury clearly leads to cell death, the secondary injury is likely to induce a spread of damage. In dorsal column and other spinal cord regions, chronic SCI often leads to degeneration, apoptosis, atrophy, and transneuronal changes [20-22]. For example, rat studies show that both neurons and glia undergo apoptosis that persists for weeks [22-25]. The same pattern is observed in monkeys after SCI, with apoptotics cells located all along the degenerating ascending and descending tracts [22]. In addition, there is an important immune component to the secondary damage, which may result from a damaged blood-brain barrier (BBB), microglial activation, and cytokine release [26]. Regardless, spinal regeneration and sprouting are often observed simultaneously after chronic SCI [20], again supporting the presence of neural plasticity as well as reactive changes $[21,27]$. 


\section{Human Studies after Chronic SCI}

Compared with experimental injury in animals, human SCI, although frequently involving damage to the dorsal columns, is less anatomically restrictive. Thus, most of the human results are derived from patients with more diffuse tissue injury than experimental SCI. Like what is seen in monkeys and rodents, somatosensory cortical plasticity also is present after chronic SCI in human beings. Cortical reorganization after chronic human SCI can be assessed by functional magnetic resonance imaging (fMRI) and transcranial magnetic stimulation (TMS) $[28,29]$.

In patients eight years after complete thoracic transection, fMRI analyses of primary somatosensory cortical activity indicate that tactile stimulation of the forelimb leads to appropriate activation in the cortical forelimb map [9]. In addition, forelimb stimulation also triggers abnormal activation in the cortical area of the denervated trunk, which is not adjacent to the forelimb map [9]. Similarly, cross-activation of the cortical map representing a denervated lower limb also is seen when the forelimb is stimulated [30]. Thus, stimulation of a body part above the SCI level causes activation of the cortex that normally represents a body part below the level. This indicates substantial reorganization of the somatosensory cortical maps after SCI [30]. Not surprisingly, this cortical reorganization also causes functional mismatches in cortical receptive and projection areas. For instance, transcortical magnetic stimulation of areas representing denervated legs evokes perceptual projection fields that remain located on the legs in patients with either complete or incomplete thoracic SCI [31]. This indicates cross-talk of the motor and sensory pathways.

Positron emission tomography (PET) and electroencephalography (EEG) are valuable tools to determine functional cortical plasticity after human SCI. PET studies can measure glucose metabolism, cerebral blood flow, oxygen metabolism, and various other physiological processes in the nervous system after injury. Chronic SCI is related to regional changes in glucose metabolism in cortical as well as subcortical regions [32]. The sequential changes suggest that SCI alters subcortical sensory input, which in turn affects cortical inhibition and excitability, and eventually leads to cortical reorganization. In measurements of cerebral blood flow by PET during a hand movement task, SCI patients show larger area of activation of somatosensory regions than normal controls. The abnormal activation extends from the cortical hand map into the cortical leg map [33]. High-resolution EEG also has been used to study cortical activation. In patients after SCI, hand movements can evoke abnormal posterior potentials in the primary somatosensory cortex, again indicating crosstalk of the motor and sensory pathways that probably result from reorganization [11].

In addition to the enlargement of somatosensory representative areas and greater excitation of the sensory cortex by locomotor activity after SCI, as discussed above for the cortex, the subcortical areas also show neural plasticity. This includes the thalamus [34-36] and spinal cord [37]. The subcortical changes could be either structural or neurochemical after chronic SCI. At the cellular level, human chronic SCI is accompanied by pathological changes such as compromised spinal circulation, edema, and increased interstitial pressure; it is typically characterized by a combination of demyelination, atrophy, degeneration, necrosis, and apoptotic changes that broadly affect spinal substrates [38-43]. Apoptosis can occur several hours to months after human SCI [44]. Immune responses also occur after human SCI that can have beneficial or detrimental consequences. Overall, human SCI is related to limited spinal regeneration or sprouting [38,45-49].

\section{NEURAL PLASTICITY AFTER ACUTE INJURY}

While the effects of chronic injuries extend over a long time lasting from many days to weeks, sensory dysfunction and abnormal feelings are likely to emerge during the first hours 
to days after injury. These sensory abnormalities might be caused by an acute reorganization of brain function.

\section{Experimental Animal Studies after Acute SCI}

Cortical functional plasticity has been studied in acute experimental SCI by electrophysiological approaches, mainly extracellular microelectrode recordings. Although there is immediate silencing of a large portion of cortical neurons in the post-central gyri after acute cervical dorsal hemisection in monkeys, tactile stimulation to an area below the lesion induces discharge in a small portion of neurons [50]. The activating effect of tactile afferents, which mainly ascend in the posterior column, suggests a topographical reorganization either in the spinal column or higher cerebral regions. This means that lower limb inputs might have ascended in the anterolateral column in these monkeys after SCI. The close-to-normal latency and summation after repetitive stimulation further support the likelihood that the new anterolateral inputs have replaced the lost dorsal column inputs [50]. These findings suggest that acute functional changes occur in the monkeys' cortex after dorsal column injury, and the input from the anterolateral column, including the spinothalamic tract, contributes to the plasticity. A potential pitfall in the experimental design, however, is that the lesion model may not be applicable without removal of spinal cord tissue and a precise anatomical margin.

The concept of "acute neuroplasticity" is further supported by studies with somatosensory evoked potentials (SEPs) indicating that SCI rapidly changes the interactions of ascending inputs [51]. The configuration of the SEPs recorded in the forelimb cortex is modulated by the preceding sensory input from the hindlimb, which serves as a conditioning stimulus. Thus, cortical SEPs from forelimb input are a sum of afferents from the forelimb and interactions between the hindlimb and forelimb. After a bilateral thoracic dorsal column lesion, the ascending dorsal column is interrupted but the anterolateral afferents from the leg remain intact. In this situation, the amplitude of the SEPs recorded in the forelimb cortex appears to be slightly enhanced, indicating that the dorsal column pathway is not solely responsible [51]. This acute enhancement is probably related to a release mechanism; whereas hindlimb input by way of the dorsal columns exerts a tonic inhibition on the firing patterns of forelimb inputs, disinhibition increases the amplitude of the cortical SEPs from the forelimb.

It is conceivable that cortical reorganization differs between complete and incomplete SCI by section in monkeys [13]. Unilateral complete section of the dorsal columns at a high cervical level leads to immediate and complete deactivation of areas $3 \mathrm{a}, 3 \mathrm{~b}$, and 1 of the somatosensory cortex that persists over a period of months. During this period, the cortical hand region is completely unresponsive to tactile stimuli, and there is a lack of a reactivation by the intact spinothalamic system. By contrast, incomplete lesions have produced different results. Immediately after partial section of the dorsal columns, which leaves a few inputs from a finger or part of the palm, the surviving afferents activate only the portions of areas $3 \mathrm{~b}$ and 1 . Over the next few weeks, however, these few afferents come to activate the rest of the hand representations in these fields, so that the hand regions soon become completely or nearly completely responsive to the preserved afferents [13]. Hand use improves over the same time period, and it often appears to approach that of normal monkeys. Thus, the reactivation and reorganization of the hand cortex by a few intact afferents represents a typical plasticity that may be functionally beneficial.

The importance of the thalamic relay is demonstrated by the block of visceral pain in cancer patients after a minor dorsal column lesion [53]. After dorsal column section and graded colorectal distension stimuli, the VPL shows selective responsiveness to visceral pain input in monkeys [52]. With respect to other subcortical substrates, there are few brainstem or 
spinal cord results on the acute effects of spinal cord injury in monkeys. Nonetheless, acute changes in neurochemistry and structure have been reported at the spinal and brainstem levels $[21,54,55]$. At the cellular level, acute SCI leads to immediate cell necrosis, lipid peroxidation, lysosomal enzyme release, and cell membrane damage [54].

\section{Human Studies after Acute SCI}

As discussed above, human SCI is seldom restricted to the dorsal column and often involves concurrent injuries that require immediate medical attention. The complexity of the lesion and acute medical intervention are confounding factors in attempts to understand the mechanisms and physiological changes after human SCI. Although limited, there is evidence that acute SCI causes cortical functional changes in human beings.

Cortical SEP analysis is a main technique used to study brain plasticity after acute SCI in human beings and a main source of existing results. For example, cortical SEPs have been studied in the early hours to first day after SCI with the goal to estimate spinal damage and predict subsequent recovery [56,57]. Alterations of the configuration of cortical SEPs have been reported, which reflect either an abnormal dorsal column function [58] or a spinothalamic tract contribution $[59,60]$. These alterations also may result from loss of cortical responses and acute reorganization. Evidence comes from the observations that changes in cortical SEP properties emerge within minutes after damage or dysfunction of the dorsal columns [61]; in addition, the sensorimotor cortex may have undergone reorganization within the first days after SCI [62].

Acute SCI leads to immediate structural and neurochemical/molecular changes in subcortical substrates in human beings. Acute structural alterations in the human spinal cord include necrosis, atrophy, apoptosis, demyelination, and edema-related changes [44,46,47,63-65]. These structural changes are reflected by a wide range of rapid neurochemical/molecular changes in such substances as amino acids, cytokines, neurotrophic factors, ions, oxygen free radicals, endogenous opiates, as well as in microglial activation [66]; many of these changes may be involved in the induction of cell death [44,64,67-69]. Functional changes also are rapidly triggered in subcortical substrates [70-72].

\section{MECHANISMS OF NEURAL PLASTICITY}

The above animal and human studies have shown that the adult body and cerebral cortex are in a constant and intimate interaction. Injuries to spinal cord that convey ascending or descending information disrupt this interaction and cause plasticity changes at the cortical level. But cortical functional changes are only one component of a larger combination of functional, structural, and neurochemical/molecular changes at multiple levels of the somatosensory core (Fig. 3) [73]. Further details of how the subcortical changes relate to cortical changes remain limited. However, clues to mechanisms by which subcortical changes may contribute to cortical changes have been found in some experimental studies. For example, after a period of time of recovery from a cut of the median nerve to the hand of monkeys, the cortex formerly activated by the glabrous hand becomes responsive to somatotopically matching parts of the dorsal hand [74]. A similar change also occurs in the cuneate nucleus of the medullary relay [75], and this recovery is relayed to the ventroposterior nucleus of the thalamus where more extensive recovery is observed [76]. Thus, when glabrous hand afferents are removed, dorsal hand afferents rapidly substitute at the brainstem and thalamic levels, which in turn contribute to cortical reorganization.

This is further supported by studies examining the neurochemical/molecular changes after SCI in spinal substrates. Plasticity changes at each level are clearly based on changes at the 
cellular level. At the center of the injury, both neurons and glia die by necrosis induced by direct insults, such as membrane disruption, vascular damage, and hemorrhage. Besides blood elements that escape from the broken vessels, recruitment of immune mediators occurs early after injury. A large number of macrophages and activated microglia are present at the lesion site. The activated microglia may participate in the apoptotic death of oligodendrocytes, which extend along the degenerating fiber tracts extending into regions far remote from the lesion [45]. It is now clear that the immune response is an important component of the secondary insult arising from SCI [26]. Although the CNS has been presumed to be an immunologically privileged organ, immune responses are easily triggered when the BBB is damaged or its permeation to peripheral factors is selectively changed. Thus, a number of cytokines, growth factors and neurotrophic factors induced by SCI can contribute to either cell death or regeneration in spinal substrates, eventually affecting the functional outcome. In our laboratory, we have measured the permeability of the BBB and the blood-spinal cord barrier (BSCB) to the cytokine tumor necrosis factor alpha (TNFa) after SCI. The transport system for TNFa at the BBB and BSCB is selectively upregulated $[77,78]$ and this enhanced entry of TNFa at one week after SCI is concurrent with sensorimotor and gait improvement of the mouse. These findings suggest that selective permeation of TNFa may facilitate functional recovery after SCI. Other factors, such as neurotrophins also are seen to promote regeneration after SCI $[79,80]$.

Several mechanisms may contribute to plasticity changes at each level after peripheral nerve and spinal cord injury. Unmasking of previously present connections and growth of new connections (collateral sprouting) are two main mechanisms proposed to explain reorganization. While growth of new connections takes time and mainly contributes to chronic plasticity changes, unmasking of previously present connections may contribute to both chronic and acute reorganization. Unmasking can be explained by several mechanisms including changes in neuronal membrane excitability, removal of local inhibition, and changes in synaptic efficacy (both excitatory and inhibitory). The synaptic changes probably involve ion channels, at least for acute changes; while chronic change involves long-term potentiation (LTP) [81]. Of the several candidate mechanisms, removal of inhibition and changes of synaptic efficacy have been favored to explain many physiological phenomena, such as underlying learning and memory, as well as cortical plasticity.

\section{Mechanisms of Acute Changes}

Unmasking of latent excitatory synapses may contribute to the rapid changes that occur within minutes to hours after transient deafferentation in human beings [82-84] or nerve lesions in animals $[85,86]$. Among several possible mechanisms, such as increased excitatory neurotransmitter release, increased density of postsynaptic receptors, decreased inhibitory input, or removal of inhibition from excitatory input, the evidence is strongest for removal of GABAergic inhibition to excitatory synapses, in mediating acute changes in plasticity [87].

GABA is the most important inhibitory neurotransmitter in the brain [88]. GABAergic neurons are conspicuous elements of cortical organization, which constitute $25 \sim 30 \%$ of the neuronal population in the motor cortex $[88,89]$. Many studies have shown that modulation of GABAergic inhibition plays a substantial role in cortical plasticity. For example, during pharmacological blockade of GABAergic inhibition in the forelimb area of the M1 representation, forelimb movements are evoked by stimulation in the adjacent vibrissa area. This finding suggests that GABAergic inhibitory circuits are crucial in maintaining or readjusting the form of cortical motor representation [90]. In addition, deafferentation of the somatosensory [91] or visual cortex [92] leads to a marked reduction in the number of neurons containing GABA or its synthesizing enzyme, glutamic acid decarboxylase, enabling these areas to retain a greater degree of plasticity than previously recognized. 
These findings suggest that modulation of GABAergic inhibition is a potential mechanism for the cortical plasticity.

Intracortical inhibition and facilitation in human beings can be assessed by the technique of paired-TMS with a subcortical conditioning pulse followed by a suprathreshold test pulse [93]. The conditioning stimulus can suppress responses produced by the test stimulus at short interstimulus intervals of 1-6 ms [93]. Similar inhibition has been observed in studies using cervical epidural recordings of the evoked corticospinal volleys [94]. This inhibition of the test stimulus by the subthreshold conditioning stimulus has been shown to be a cortical phenomenon. However, the intracortical inhibition is reduced when the subthreshold conditioning TMS pulse is applied to the biceps muscle during transient deafferentation, while the motor threshold remains unchanged. These changes are thought to be related to a reduction in GABAergic inhibition, since drugs that enhance GABAergic inhibition can increase intracortical inhibition but have no effect on TMS motor threshold $[95,96]$. These findings suggest that changes in GABAergic inhibition can be rapidly induced in human beings after injury, indicating rapid cortical plasticity.

\section{Mechanisms for Chronic Changes}

Plasticity that occurs over a longer time likely involves mechanisms in addition to the unmasking of latent synapses. Following Hebbian rules [97], a commonly used model to explain important features of plasticity [98], experience-dependent cortical plasticity usually involves changes of synaptic efficacy, another important mechanism contributing to cortical plasticity after peripheral nerve and spinal cord injury. It has been shown that LTP at the synapses of horizontal collaterals influences cortical plasticity by increasing cortical synaptic efficacy $[99,100]$. Axonal regeneration and sprouting with alterations in synapse shape, number, size and type also may be involved[7].

LTP is the fundamental cellular mechanism for learning in the hippocampus, and this has also been shown in normal somatosensory, motor, and visual cortices [101]. Use-dependent sensorimotor learning mechanisms, including LTP, have been shown to contribute to cortical plasticity during skills learning, even after supraspinal injury [102]. The connections across the primary motor cortex are strengthened by LTP that produces excitatory synaptic transmission in both the horizontal cortico-cortical connections and ascending cortical pathways $[103,104]$. Moreover, motor learning also involves the formation of connections between the sensory cortex and the motor cortex [105]. Similarly, the connections are diffuse at first, producing contraction of unnecessary muscles, but become specific by producing LTP through practice. During this period of time, increases in cortical synaptic efficacy among the neuronal assemblies are likely to accompany the reorganization. These studies suggest that LTP might be involved in the mechanisms of functional cortical plasticity during motor learning after SCI.

Slow and large-scale map changes also involve anatomical changes, such as the growth of new horizontal connections, the expansion of axonal arbors, or structural alterations of synapses, as shown in several sensory areas in different animal models [106-108]. Members of the growth factor families might play a crucial role in axonal sprouting. For example, neural activity associated with physical activity in rodents has greatly increased the expression of neurotrophins such as brain-derived neurotrophic factors and nerve growth factors [109]. This expression likely affects the molecular and cellular events that influence cortical plasticity, including greater synaptic efficacy and axonal sprouting. 


\section{FUNCTIONAL SIGNIFICANCE OF PLASTICITY AFTER INJURY}

The experimental and clinical results described in the preceding sections indicate that plasticity reorganization occurs in the mammalian cortex in response to peripheral and central injury. Thus, it raises the important question of whether such reorganization may play a functionally compensatory role, or on the contrary, be harmful.

The functional role of reorganization after peripheral never injury still remains unclear. However, there is evidence that the reorganization may play a compensatory role. For instance, reactivation of cortical neurons by the remaining peripheral input from a skin surface is shown to result in improved sensory perception and discrimination [73]. In this case, the reactivated neurons would be reassigned to functional circuits mediating perceptions from the innervated skin. Additionally, in some studies when training or sensory experience lead to an increase in the size of cortical representations, improved behavioral performances also are observed [110-112]. Similarly, there also is evidence that cortical plasticity after central injury plays a functionally compensatory role. For example, visually deprived cats perform better at sound localization than normal cats. In human beings, hearing and sound localization also may be better in blind than in sighted subjects. Although these plasticity changes cannot compensate for visual loss, they are particularly useful in enhancing other sensory perceptions. Another example is that plasticity reorganization of the brain after stroke leads to functional improvement.

Nevertheless, these ideas are speculative because in most situations the functional significance of reorganization after injury remains to be demonstrated. For instance, when the reactivated neurons are neither integrated into functionally relevant circuits nor distinguished from their original sources, misperceptions occur and persist. Thus, human beings with a missing limb typically feel that the missing limb is still present, and touch on the stump of the limb or on the face also may be felt on the missing limb [113]. The reasonable explanation is that cortical neurons are abnormally activated by input from intact parts of the body, and they continue to contribute to cortical circuits that are normally activated by stimuli from the missing parts of the body [114]. Although most of these misperceptions are easily tolerated, some patients with the perception of pain in missing limbs (phantom pain) are less fortunate. Therefore, it is important to be able to promote or prevent cortical reorganization at different periods of time after injury so as to obtain the most desirable clinical outcome [115].

\section{CONCLUSION}

Experimental and clinical studies have demonstrated that structural and functional plasticity occurs in the adult nervous system in response to spinal cord injury. These plasticity changes occur at multiple levels: cortical, subcortical, brainstem, and spinal cord. Although the interaction of the plasticity changes at each level has not been extensively studied, it is probable that changes at the subcortical level contribute to cortical reorganization. The short-term reorganization that is rapidly induced by acute injury is probably based on the mechanism of the unmasking of latent synapses because of modulation of neurotransmitters, particularly GABAergic inhibition. By contrast, the long-term changes after chronic injury may involve changes of synaptic efficacy induced by LTP, axonal regeneration, and sprouting with the expression of neurotrophins and other growth factors. It is important to identify which plasticity changes are beneficial and which ones may be harmful. A better understanding of the mechanisms of plasticity should facilitate the design of appropriate strategies to modulate plasticity changes and eventually promote recovery of function after SCI. 


\section{Acknowledgments}

WP is sponsored by NINDS R01s (NS 45751 and NS46528). AJK receives support from NIH DK 54880 and AA12865. We appreciate the institutional support from Pennington Biomedical Research Center.

\section{References}

References 116-118 are related articles recently published in Current Pharmaceutical Design.

1. Fry EJ. Central nervous system regeneration: mission impossible? Clin Exp Pharmacol Physiol. 2001; 28:253. [PubMed: 11251636]

2. Burns SP, Golding DG, Rolle WA Jr, Graziani V, Ditunno JF Jr. Recovery of ambulation in motorincomplete tetraplegia. Arch Phys Med Rehabil. 1997; 78:1169. [PubMed: 9365343]

3. Waters RL, Adkins RH, Sie IH, Yakura JS. Motor recovery following spinal cord injury associated with cervical spondylosis: a collaborative study. Spinal Cord. 1996; 34:711. [PubMed: 8961427]

4. Blight AR. Remyelination, revascularization, and recovery of function in experimental spinal cord injury. Adv Neurol. 1993; 59:91. [PubMed: 8420127]

5. Little JW, Ditunno JF Jr, Stiens SA, Harris RM. Incomplete spinal cord injury: neuronal mechanisms of motor recovery and hyperreflexia. Arch Phys Med Rehabil. 1999; 80:587. [PubMed: 10326926]

6. Donoghue JP. Plasticity of adult sensorimotor representations. Curr Opin Neurobiol. 1995; 5:749. [PubMed: 8805413]

7. Kaas JH. Plasticity of sensory and motor maps in adult mammals. Annu Rev Neurosci. 1991; 14:137. [PubMed: 2031570]

8. Jang SH, Kim YH, Cho SH, Chang Y, Lee ZI, Ha JS. Cortical reorganization associated with motor recovery in hemiparetic stroke patients. Neuroreport. 2003; 14:1305. [PubMed: 12876462]

9. Moore CI, Stern CE, Dunbar C, Kostyk SK, Gehi A, Corkin S. Referred phantom sensations and cortical reorganization after spinal cord injury in humans. Proc Natl Acad Sci USA. 2000; 97:14703. [PubMed: 11114177]

10. Jones EG. Cortical and subcortical contributions to activity-dependent plasticity in primate somatosensory cortex. Annu Rev Neurosci. 2000; 23:1. [PubMed: 10845057]

11. Green JB, Sora E, Bialy Y, Ricamato A, Thatcher RW. Cortical motor reorganization after paraplegia: an EEG study. Neurology. 1999; 53:736. [PubMed: 10489034]

12. Jain N, Florence SL, Qi HX, Kaas JH. Growth of new brainstem connections in adult monkeys with massive sensory loss. Proc Natl Acad Sci USA. 2000; 97:5546. [PubMed: 10779564]

13. Jain N, Catania KC, Kaas JH. Deactivation and reactivation of somatosensory cortex after dorsal spinal cord injury. Nature. 1997; 386:495. [PubMed: 9087408]

14. Wu CW, Kaas JH. Reorganization in primary motor cortex of primates with long-standing therapeutic amputations. J Neurosci. 1999; 19:7679. [PubMed: 10460274]

15. Donoghue JP, Suner S, Sanes JN. Dynamic organization of primary motor cortex output to target muscles in adult rats. II. Rapid reorganization following motor nerve lesions. Exp Brain Res. 1990; 79:492. [PubMed: 2340869]

16. Sanes JN, Suner S, Donoghue JP. Dynamic organization of primary motor cortex output to target muscles in adult rats. I. Long-term patterns of reorganization following motor or mixed peripheral nerve lesions. Exp Brain Res. 1990; 79:479. [PubMed: 2340868]

17. Qi HX, Stepniewska I, Kaas JH. Reorganization of primary motor cortex in adult macaque monkeys with long-standing amputations. J Neurophysiol. 2000; 84:2133. [PubMed: 11024101]

18. Nudo RJ, Milliken GW. Reorganization of movement representations in primary motor cortex following focal ischemic infarcts in adult squirrel monkeys. J Neurophysiol. 1996; 75:2144. [PubMed: 8734610]

19. Raineteau O, Schwab ME. Plasticity of motor systems after incomplete spinal cord injury. Nat Rev Neurosci. 2001; 2:263. [PubMed: 11283749] 
20. Bernstein ME, Bernstein JJ. Regeneration of axons and synaptic complex formation rostral to the site of hemisection in the spinal cord of the monkey. Int J Neurosci. 1973; 5:15. [PubMed: 4121387]

21. Bresnahan JC. An electron-microscopic analysis of axonal alterations following blunt contusion of the spinal cord of the rhesus monkey (Macaca mulatta). J Neurol Sci. 1978; 37:59. [PubMed: 99494]

22. Crowe MJ, Bresnahan JC, Shuman SL, Masters JN, Beattie MS. Apoptosis and delayed degeneration after spinal cord injury in rats and monkeys. Nat Med. 1997; 3:73. [PubMed: 8986744]

23. Lou J, Lenke LG, Ludwig FJ, O'Brien MF. Apoptosis as a mechanism of neuronal cell death following acute experimental spinal cord injury. Spinal Cord. 1998; 36:683. [PubMed: 9800272]

24. Yong C, Arnold PM, Zoubine MN, Citron BA, Watanabe I, Berman NE, et al. Apoptosis in cellular compartments of rat spinal cord after severe contusion injury. J Neurotrauma. 1998; 15:459. [PubMed: 9674550]

25. Liu XZ, Xu XM, Hu R, Du C, Zhang SX, McDonald JW, et al. Neuronal and glial apoptosis after traumatic spinal cord injury. J Neurosci. 1997; 17:5395. [PubMed: 9204923]

26. Popovich PG, Wei P, Stokes BT. Cellular inflammatory response after spinal cord injury in Sprague-Dawley and Lewis rats. J Comp Neurol. 1997; 377:443. [PubMed: 8989657]

27. Bullitt E, Stofer WD, Vierck CJ, Perl ER. Reorganization of primary afferent nerve terminals in the spinal dorsal horn of the primate caudal to anterolateral chordotomy. J Comp Neurol. 1988; 270:549. [PubMed: 3372746]

28. Levy WJ Jr, Amassian VE, Traad M, Cadwell J. Focal magnetic coil stimulation reveals motor cortical system reorganized in humans after traumatic quadriplegia. Brain Res. 1990; 510:130. [PubMed: 2322837]

29. Topka H, Cohen LG, Cole RA, Hallett M. Reorganization of corticospinal pathways following spinal cord injury. Neurology. 1991; 41:1276. [PubMed: 1866018]

30. Perani D, Brunelli GA, Tettamanti M, Scifo P, Tecchio F, Rossini PM, et al. Remodelling of sensorimotor maps in paraplegia: a functional magnetic resonance imaging study after a surgical nerve transfer. Neurosci Lett. 2001; 303:62. [PubMed: 11297824]

31. Cohen LG, Topka H, Cole RA, Hallett M. Leg paresthesias induced by magnetic brain stimulation in patients with thoracic spinal cord injury. Neurology. 1991; 41:1283. [PubMed: 1866019]

32. Roelcke U, Curt A, Otte A, Missimer J, Maguire RP, Dietz V, et al. Influence of spinal cord injury on cerebral sensorimotor systems: a PET study. J Neurol Neurosurg Psychiatry. 1997; 62:61. [PubMed: 9010401]

33. Bruehlmeier M, Dietz V, Leenders KL, Roelcke U, Missimer J, Curt A. How does the human brain deal with a spinal cord injury? Eur J Neurosci. 1998; 10:3918. [PubMed: 9875370]

34. Hua SE, Garonzik IM, Lee JI, Lenz FA. Microelectrode studies of normal organization and plasticity of human somatosensory thalamus. J Clin Neurophysiol. 2000; 17:559. [PubMed: 11151975]

35. Lenz FA, Kwan HC, Dostrovsky JO, Tasker RR. Characteristics of the bursting pattern of action potentials that occurs in the thalamus of patients with central pain. Brain Res. 1989; 496:357. [PubMed: 2804648]

36. Lenz FA, Kwan HC, Martin R, Tasker R, Richardson RT, Dostrovsky JO. Characteristics of somatotopic organization and spontaneous neuronal activity in the region of the thalamic principal sensory nucleus in patients with spinal cord transection. J Neurophysiol. 1994; 72:1570. [PubMed: 7823087]

37. Calancie B, Lutton S, Broton JG. Central nervous system plasticity after spinal cord injury in man: interlimb reflexes and the influence of cutaneous stimulation. Electroencephalogr. Clin Neurophysiol. 1996; 101:304.

38. Beattie MS, Farooqui AA, Bresnahan JC. Review of current evidence for apoptosis after spinal cord injury. J Neurotrauma. 2000; 17:915. [PubMed: 11063057]

39. Becerra JL, Puckett WR, Hiester ED, Quencer RM, Marcillo AE, Post MJ, et al. MR-pathologic comparisons of wallerian degeneration in spinal cord injury. AJNR Am J Neuroradiol. 1995; 16:125. [PubMed: 7900580] 
40. Bunge RP, Puckett WR, Becerra JL, Marcillo A, Quencer RM. Observations on the pathology of human spinal cord injury. A review and classification of 22 new cases with details from a case of chronic cord compression with extensive focal demyelination. Adv Neurol. 1993; 59:75. [PubMed: 8420126]

41. Croul SE, Flanders AE. Neuropathology of human spinal cord injury. Adv Neurol. 1997; 72:317. [PubMed: 8993708]

42. Jimenez O, Marcillo A, Levi AD. A histopathological analysis of the human cervical spinal cord in patients with acute traumatic central cord syndrome. Spinal Cord. 2000; 38:532. [PubMed: 11035473]

43. Martin JE, Mather KS, Swash M, Garofalo O, Dale GE, Leigh PN, et al. Spinal cord trauma in man: studies of phosphorylated neurofilament and ubiquitin expression. Brain. 1990; 113:1553. [PubMed: 1700924]

44. Emery E, Aldana P, Bunge MB, Puckett W, Srinivasan A, Keane RW, et al. Apoptosis after traumatic human spinal cord injury. J Neurosurg. 1998; 89:911. [PubMed: 9833815]

45. Beattie MS, Li Q, Bresnahan JC. Cell death and plasticity after experimental spinal cord injury. Prog Brain Res. 2000; 128:9. [PubMed: 11105665]

46. Kakulas BA. A review of the neuropathology of human spinal cord injury with emphasis on special features. J Spinal Cord Med. 1999; 22:119. [PubMed: 10826269]

47. Kakulas BA. The applied neuropathology of human spinal cord injury. Spinal Cord. 1999; 37:79. [PubMed: 10065745]

48. Tuszynski MH, Gabriel K, Gerhardt K, Szollar S. Human spinal cord retains substantial structural mass in chronic stages after injury. J Neurotrauma. 1999; 16:523. [PubMed: 10391368]

49. Wang ZH, Walter GF, Gerhard L. The expression of nerve growth factor receptor on Schwann cells and the effect of these cells on the regeneration of axons in traumatically injured human spinal cord. Acta Neuropathol (Berl). 1996; 91:180. [PubMed: 8787152]

50. Andersson SA, Finger S, Norrsell U. Cerebral units activated by tactile stimuli via a ventral spinal pathway in monkeys. Acta Physiol Scand. 1975; 93:119. [PubMed: 808102]

51. Simpson RK Jr, Blackburn JG, Martin HF III, Katz S. The effects of spinal cord injury on somatosensory evoked potentials produced by interactions between afferent pathways. Neurol Res. 1983; 5:39. [PubMed: 6139763]

52. Al Chaer ED, Feng Y, Willis WD. A role for the dorsal column in nociceptive visceral input into the thalamus of primates. J Neurophysiol. 1998; 79:3143. [PubMed: 9636114]

53. Willis WD, Al Chaer ED, Quast MJ, Westlund KN. A visceral pain pathway in the dorsal column of the spinal cord. Proc Natl Acad Sci USA. 1999; 96:7675. [PubMed: 10393879]

54. Abraham J, Balasubramanian AS, Theodore DR, Nagarajan S, Apte CA, Chandi S. Spinal cord edema, 5-hydroxytryptamine, lipid peroxidation, and lysosomal enzyme release after acute contusion and compression injury in primates. Cent Nerv Syst Trauma. 1985; 2:45. [PubMed: 2418983]

55. Kuruvilla A, Theodore DR, Abraham J. Changes in norepinephrine and histamine in monkey spinal cords traumatized by weight drop and compression. Cent Nerv Syst Trauma. 1985; 2:61. [PubMed: 4092239]

56. Katz RT, Toleikis RJ, Knuth AE. Somatosensory-evoked and dermatomal-evoked potentials are not clinically useful in the prognostication of acute spinal cord injury. Spine. 1991; 16:730. [PubMed: 1925746]

57. Macdonell RA, Donnan GA. Magnetic cortical stimulation in acute spinal cord injury. Neurology. 1995; 45:303. [PubMed: 7854530]

58. Cheliout-Heraut F, Loubert G, Masri-Zada T, Aubrun F, Pasteyer J. Evaluation of early motor and sensory evoked potentials in cervical spinal cord injury. Neurophysiol Clin. 1998; 28:39. [PubMed: 9562998]

59. Ziganow S. Neurometric evaluation of the cortical somatosensory evoked potential in acute incomplete spinal cord injuries. Electroencephalogr Clin Neurophysiol. 1986; 65:86. [PubMed: 2419107]

60. Li C, Houlden DA, Rowed DW. Somatosensory evoked potentials and neurological grades as predictors of outcome in acute spinal cord injury. J Neurosurg. 1990; 72:600. [PubMed: 2319320] 
61. Schubert A, Todd MM, Luerssen TG, Hicks GE. Loss of intraoperative evoked responses during dorsal column surgery associated with isolated postoperative sensory deficit. J Clin Monit. 1987; 3:277. [PubMed: 3681361]

62. Streletz LJ, Belevich JK, Jones SM, Bhushan A, Shah SH, Herbison GJ. Transcranial magnetic stimulation: cortical motor maps in acute spinal cord injury. Brain Topogr. 1995; 7:245. [PubMed: 7599023]

63. Kilburn MP, Hadley MN. Contemporary treatment paradigms in spinal injury. Clin Neurosurg. 2000; 46:153. [PubMed: 10944674]

64. Lu J, Ashwell KW, Waite P. Advances in secondary spinal cord injury: role of apoptosis. Spine. 2000; 25:1859. [PubMed: 10888960]

65. Selden NR, Quint DJ, Patel N, d'Arcy HS, Papadopoulos SM. Emergency magnetic resonance imaging of cervical spinal cord injuries: clinical correlation and prognosis. Neurosurgery. 1999; 44:785. [PubMed: 10201304]

66. Amar AP, Levy ML. Pathogenesis and pharmacological strategies for mitigating secondary damage in acute spinal cord injury. Neurosurgery. 1999; 44:1027. [PubMed: 10232536]

67. Cuevas P, Carceller F. Therapeutic implications of fibroblast growth factors in traumatic spinal cord injury. Neurol Res. 2001; 23:207. [PubMed: 11320601]

68. Tator $\mathrm{CH}$. Biology of neurological recovery and functional restoration after spinal cord injury. Neurosurgery. 1998; 42:696. [PubMed: 9574633]

69. Yezierski RP. Pain following spinal cord injury: pathophysiology and central mechanisms. Prog Brain Res. 2000; 129:429. [PubMed: 11098709]

70. Leis AA, Kronenberg MF, Stetkarova I, Paske WC, Stokic DS. Spinal motoneuron excitability after acute spinal cord injury in humans. Neurology. 1996; 47:231. [PubMed: 8710084]

71. Hiersemenzel LP, Curt A, Dietz V. From spinal shock to spasticity: neuronal adaptations to a spinal cord injury. Neurology. 2000; 54:1574. [PubMed: 10762496]

72. Delwaide PJ, Pennisi G. Tizanidine and electrophysiologic analysis of spinal control mechanisms in humans with spasticity. Neurology. 1994; 44:S21. [PubMed: 7970007]

73. Wall JT, Xu J, Wang X. Human brain plasticity: an emerging view of the multiple substrates and mechanisms that cause cortical changes and related sensory dysfunctions after injuries of sensory inputs from the body. Brain Res Brain Res Rev. 2002; 39:181. [PubMed: 12423766]

74. Schroeder CE, Seto S, Arezzo JC, Garraghty PE. Electrophysiological evidence for overlapping dominant and latent inputs to somatosensory cortex in squirrel monkeys. J Neurophysiol. 1995; 74:722. [PubMed: 7472377]

75. Xu J, Wall JT. Rapid changes in brainstem maps of adult primates after peripheral injury. Brain Res. 1997; 774:211. [PubMed: 9452211]

76. Garraghty PE, Kaas JH. Large-scale functional reorganization in adult monkey cortex after peripheral nerve injury. Proc Natl Acad Sci USA. 1991; 88:6976. [PubMed: 1871112]

77. Pan W, Zhang L, Liao J, Csernus B, Kastin AJ. Selective increase in TNF alpha permeation across the blood-spinal cord barrier after SCI. J Neuroimmunol. 2003; 134:111. [PubMed: 12507778]

78. Pan W, Kastin AJ, Bell RL, Olson RD. Upregulation of tumor necrosis factor alpha transport across the blood-brain barrier after acute compressive spinal cord injury. J Neurosci. 1999; 19:3649. [PubMed: 10212323]

79. Liu Y, Himes BT, Murray M, Tessler A, Fischer I. Grafts of BDNF-producing fibroblasts rescue axotomized rubrospinal neurons and prevent their atrophy. Exp Neurol. 2002; 178:150. [PubMed: 12504875]

80. Sayer FT, Oudega M, Hagg T. Neurotrophins reduce degeneration of injured ascending sensory and corticospinal motor axons in adult rat spinal cord. Exp Neurol. 2002; 175:282. [PubMed: 12009779]

81. Ziemann U, Hallett M, Cohen LG. Mechanisms of deafferentation-induced plasticity in human motor cortex. J Neurosci. 1998; 18:7000. [PubMed: 9712668]

82. Brasil-Neto JP, Valls-Sole J, Pascual-Leone A, Cammarota A, Amassian VE, Cracco R, Maccabee $\mathrm{P}$, et al. Rapid modulation of human cortical motor outputs following ischaemic nerve block. Brain. 1993; 116:511. [PubMed: 8513390] 
83. Sadato N, Zeffiro TA, Campbell G, Konishi J, Shibasaki H, Hallett M. Regional cerebral blood flow changes in motor cortical areas after transient anesthesia of the forearm. Ann Neurol. 1995; 37:74. [PubMed: 7818261]

84. Brasil-Neto JP, Cohen LG, Pascual-Leone A, Jabir FK, Wall RT, Hallett M. Rapid reversible modulation of human motor outputs after transient deafferentation of the forearm: a study with transcranial magnetic stimulation. Neurology. 1992; 42:1302. [PubMed: 1620338]

85. Merzenich MM, Kaas JH, Wall JT, Sur M, Nelson RJ, Felleman DJ. Progression of change following median nerve section in the cortical representation of the hand in areas $3 \mathrm{~b}$ and 1 in adult owl and squirrel monkeys. Neuroscience. 1983; 10:639. [PubMed: 6646426]

86. Nicolelis MA, Lin RC, Woodward DJ, Chapin JK. Induction of immediate spatiotemporal changes in thalamic networks by peripheral block of ascending cutaneous information. Nature. 1993; 361:533. [PubMed: 8429906]

87. Chen R, Cohen LG, Hallett M. Nervous system reorganization following injury. Neuroscience. 2002; 111:761. [PubMed: 12031403]

88. Jones EG. GABAergic neurons and their role in cortical plasticity in primates. Cereb Cortex. 1993; 3:361. [PubMed: 8260806]

89. Gilbert CD, Wiesel TN. Receptive field dynamics in adult primary visual cortex. Nature. 1992; 356:150. [PubMed: 1545866]

90. Jacobs KM, Donoghue JP. Reshaping the cortical motor map by unmasking latent intracortical connections. Science. 1991; 251:944. [PubMed: 2000496]

91. Welker E, Soriano E, Van der LH. Plasticity in the barrel cortex of the adult mouse: effects of peripheral deprivation on GAD-immunoreactivity. Exp Brain Res. 1989; 74:441. [PubMed: 2707320]

92. Hendry SH, Jones EG. Reduction in number of immunostained GABAergic neurones in deprivedeye dominance columns of monkey area 17. Nature. 1986; 20:750. [PubMed: 3703001]

93. Kujirai T, Caramia MD, Rothwell JC, Day BL, Thompson PD, Ferbert A, et al. Corticocortical inhibition in human motor cortex. J Physiol. 1993; 471:501. [PubMed: 8120818]

94. Nakamura H, Kitagawa H, Kawaguchi Y, Tsuji H. Intracortical facilitation and inhibition after transcranial magnetic stimulation in conscious humans. J Physiol. 1997; 498:817. [PubMed: 9051592]

95. Ziemann U, Lonnecker S, Steinhoff BJ, Paulus W. Effects of antiepileptic drugs on motor cortex excitability in humans: a transcranial magnetic stimulation study. Ann Neurol. 1996; 40:367. [PubMed: 8797526]

96. Ziemann U, Lonnecker S, Steinhoff BJ, Paulus W. The effect of lorazepam on the motor cortical excitability in man. Exp Brain Res. 1996; 109:127. [PubMed: 8740215]

97. Rauschecker JP. Developmental plasticity and memory. Behav Brain Res. 1995; 66:7. [PubMed: 7755902]

98. Rauschecker JP. Mechanisms of visual plasticity: Hebb synapses, NMDA receptors, and beyond. Physiol Rev. 1991; 71:587. [PubMed: 1826058]

99. Hess G, Donoghue JP. Long-term depression of horizontal connections in rat motor cortex. Eur J Neurosci. 1996; 8:658. [PubMed: 9081617]

100. Hess G, Donoghue JP. Long-term potentiation and long-term depression of horizontal connections in rat motor cortex. Acta Neurobiol Exp (Wars). 1996; 56:397. [PubMed: 8787200]

101. Malenka RC, Nicoll RA. Long-term potentiation--a decade of progress? Science. 1999; 285:1870. [PubMed: 10489359]

102. Dobkin BH. Activity-dependent learning contributes to motor recovery. Ann Neurol. 1998; 44:158. [PubMed: 9708536]

103. Donoghue JP. Limits of reorganization in cortical circuits. Cereb Cortex. 1997; 7:97. [PubMed: 9087818]

104. Hess G, Aizenman CD, Donoghue JP. Conditions for the induction of long-term potentiation in layer II/III horizontal connections of the rat motor cortex. J Neurophysiol. 1996; 75:1765. [PubMed: 8734579] 
105. Asanuma H, Pavlides C. Neurobiological basis of motor learning in mammals. Neuroreport. 1997; 8:i. [PubMed: 9141042]

106. Das A, Gilbert CD. Long-range horizontal connections and their role in cortical reorganization revealed by optical recording of cat primary visual cortex. Nature. 1995; 375:780. [PubMed: 7596409]

107. Darian-Smith C, Gilbert CD. Axonal sprouting accompanies functional reorganization in adult cat striate cortex. Nature. 1994; 368:737. [PubMed: 8152484]

108. Florence SL, Taub HB, Kaas JH. Large-scale sprouting of cortical connections after peripheral injury in adult macaque monkeys. Science. 1998; 282:1117. [PubMed: 9804549]

109. Neeper SA, Gomez-Pinilla F, Choi J, Cotman CW. Physical activity increases mRNA for brainderived neurotrophic factor and nerve growth factor in rat brain. Brain Res. 1996; 726:49. [PubMed: 8836544]

110. Recanzone GH, Merzenich MM, Jenkins WM, Grajski KA, Dinse HR. Topographic reorganization of the hand representation in cortical area $3 \mathrm{~b}$ owl monkeys trained in a frequencydiscrimination task. J Neurophysiol. 1992; 67:1031. [PubMed: 1597696]

111. Xerri C, Stern JM, Merzenich MM. Alterations of the cortical representation of the rat ventrum induced by nursing behavior. J Neurosci. 1994; 14:1710. [PubMed: 8126565]

112. Zohary E, Celebrini S, Britten KH, Newsome WT. Neuronal plasticity that underlies improvement in perceptual performance. Science. 1994; 263:1289. [PubMed: 8122114]

113. Ramachandran VS, Hirstein W. The perception of phantom limbs. The D. O. Hebb lecture. Brain. 1998; 121:1603. [PubMed: 9762952]

114. Davis KD, Kiss ZH, Luo L, Tasker RR, Lozano AM, Dostrovsky JO. Phantom sensations generated by thalamic microstimulation. Nature. 1998; 391:385. [PubMed: 9450753]

115. Kilgard MP, Merzenich MM. Cortical map reorganization enabled by nucleus basalis activity. Science. 1998; 279:1714. [PubMed: 9497289]

116. Carlson HA. Protein flexibility is an important component of structure-based drug discovery. Curr Pharm Design. 2002; 8(17):1571-8.

117. Kastin AJ, Pan W. Feeding peptides interact in several ways with the blood-brain barrier. Curr Pharm Design. 2003; 9(10):789-94.

118. Pan W, Kastin AJ. Interactions of cytokines with the blood-brain barrier: implications for feeding. Curr Pharm Design. 2003; 9(10):827-31.

\section{ABBREVIATIONS}

$\begin{array}{ll}\text { BBB } & \text { Blood-Brain Barrier } \\ \text { BSCB } & \text { Blood-Spinal Cord Barrier } \\ \text { CNS } & \text { Central Nervous System } \\ \text { EEG } & \text { Electroencephalography } \\ \text { fMRI } & \text { functional Magnetic Resonance Imaging } \\ \text { LTP } & \text { Long-Term Potentiation } \\ \text { PET } & \text { Positron Emission Tomography } \\ \text { SCI } & \text { Spinal Cord Injury } \\ \text { SEPs } & \text { Somatosensory Evoked Potentials } \\ \text { TMS } & \text { Transcranial Magnetic Stimulation } \\ \text { TNF } & \text { Tumor Necrosis Factor } \\ \text { VPL } & \text { Ventroposterior Lateral Nucleus }\end{array}$




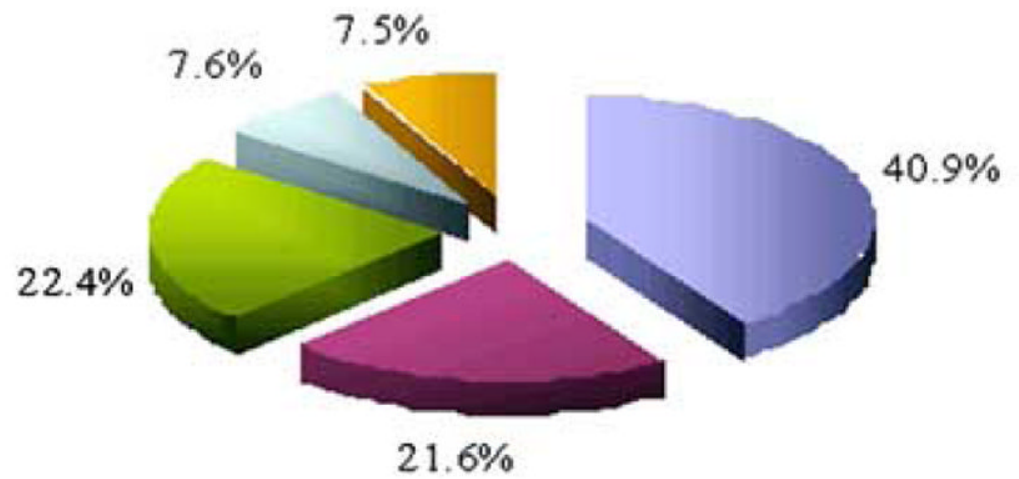

Vehicular crashes a Violence a Falls a Others a Sports

Fig. (1).

Etiology of SCI since 1990. 

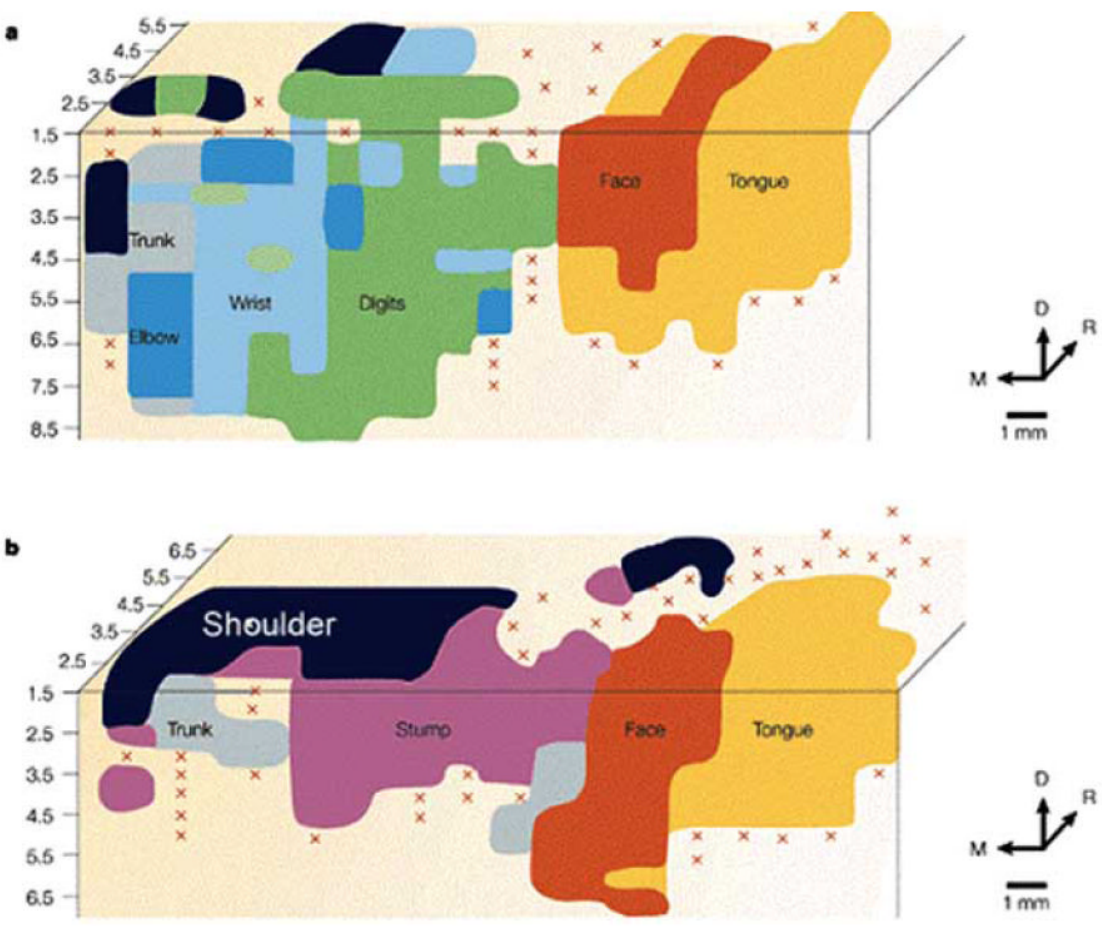

Fig. (2).

Organization of the motor cortex.

a. Normal macaque monkey. B. Macaque monkey with long-standing amputation of a forelimb. These partial motor output maps include the representation of the face to the upper trunk. X indicates that no response could be elicited. (D, dorsal; M, medial; R, rostral.) (Adapted with permission from Raineteau et al., Ref. 19. ( 2001 Nature Publishing Group). 


\section{SPINAL CORD INJURY}

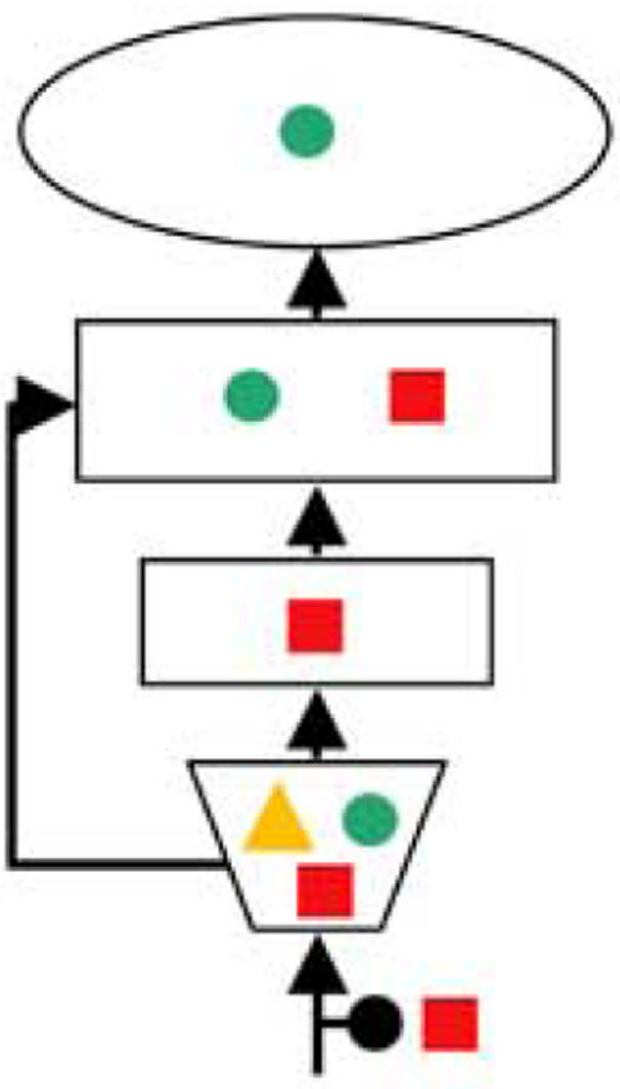

CORTEX

THALAMUS

BRAINSTEM

SPINAL CORD

Type of change

PEREPHERAL SENSORY NEURON

\section{Structural}

Functional

Molecular

Fig. (3).

Evidences of changes at each level of the somatosensory core after chronic SCI. A symbol indicates there is evidence for that particular type of change at the level. No symbol indicates lack of evidence for that type of change at that level. (Information extracted from Wall et al., Ref. 73, Fig. 3c. () 2002 Elsevier Science B.V.). 